\title{
An overview of the National Health Insurance and its possible impact on eye healthcare services in South Africa
}

\author{
Author: \\ H. Lawrence Sithole \\ Affiliation: \\ ${ }^{1}$ School of Interdisciplinary \\ Research and Graduate \\ Studies, University of South \\ Africa, South Africa \\ Correspondence to: \\ Lawrence Sithole \\ Email: \\ sithohl@unisa.ac.za \\ Postal address: \\ PO Box 392, Pretoria 0003, \\ South Africa \\ Dates: \\ Received: 20 Aug. 2014 \\ Accepted: 11 Nov. 2014 \\ Published: 30 Apr. 2015 \\ How to cite this article: \\ Sithole HL. An overview \\ of the National Health \\ Insurance and its possible \\ impact on eye healthcare \\ services in South Africa. \\ Afr. Vision Eye Health. \\ 2015;74(1), Art. \#18, 6 pages. \\ http://dx.doi.org/10.4102/ \\ aveh.v74i1.18

\section{Copyright:} \\ (C) 2015. The Author(s). \\ Licensee: AOSIS \\ OpenJournals. This work is \\ licensed under the Creative \\ Commons Attribution \\ License.
}

Read online: code with your smart phone or mobile device to read online.
The National Health Insurance (NHI) is an important development that underpins democracy in South Africa. It aims to redress the inequities of public healthcare delivery by implementing transformational policies towards establishing inclusive public healthcare coverage for the entire population of South Africa, with more emphasis on health promotion. The implementation of this initiative has created some hope amongst primary eye healthcare professionals, such as optometrists, that their profession may finally be given the recognition it deserves. Although the government is contemplating introducing a new directorate for eye healthcare and forming an advisory committee on eye healthcare reporting to the Minister of Health, the extent to which eye healthcare will be incorporated into the NHI is currently not clear. It is believed that the white paper on the NHI will shed some light on these issues. Unfortunately, current indications are that the initiative has serious challenges to overcome such as poor infrastructure, budgetary constraints and lack of interest from other healthcare professionals. Furthermore, corruption issues may also need to be addressed if the NHI is to be implemented successfully. Nevertheless, the NHI remains a positive proposition for universal health coverage for the people of South Africa, and there is hope that primary eye care providers, such as optometrists and other eye care professionals, will also play a greater role in the NHI than they currently do in the public healthcare system.

\section{Introduction}

A great healthcare transformation, in the form of National Health Insurance (NHI) in the public and private healthcare sectors, is developing in South Africa. The aim of the NHI is to promote access to healthcare amongst all South African citizens, irrespective of their ability to pay for services, in the hope of increasing the utilisation of healthcare services for better health. In 2001, African governments committed to increase investments in health to $15 \%$ of national budgets by $2015 .{ }^{1}$ Following this commitment, Ghana introduced its NHI scheme in 2003, which is now operating across all districts in the country. ${ }^{2}$ Other African countries that have since made initiatives to improve healthcare services by introducing universal healthcare coverage via NHI include Rwanda, Nigeria, Ghana, Zambia and Tanzania. ${ }^{1,2,3,4,5}$ It is therefore expected that South Africa, as the second largest economy in Africa, following Nigeria, ${ }^{6}$ will play a leading role in introducing universal health coverage for its citizens in the form of the NHI. The NHI further provides a favourable platform for eye healthcare practitioners such as optometrists to make a meaningful contribution towards the envisaged new primary healthcare (PHC) approach in South Africa.

\section{The National Health Plan for South Africa}

The state of healthcare and healthcare systems in South Africa is currently presented with major challenges such as poor infrastructure, inadequate human resources, inequalities in funding, and poor governance. Unfortunately, these challenges are a result of the healthcare system in place during the apartheid era in South Africa. ${ }^{7}$ The public health system was aimed at sustaining racial segregation and promulgating racist legislation. During this era, healthcare services were racially based, with more resources allocated for the white minority and less resources allocated for the black majority. The end result was a healthcare system that was curative in approach, thus increasing the burden of disease amongst South Africans. Also, the system encouraged the development of two separate healthcare systems, namely public healthcare facilities for the poor, and private healthcare facilities for the more affluent. Consequently, after the inception of democracy in 1994, the new government, under the auspices of the late former president Nelson Mandela, adopted a dysfunctional healthcare system that was detrimental to the people of South Africa. Unfortunately, the status quo has direct consequences on how eye healthcare services are currently delivered in South Africa. Eye healthcare services are also divided into public eye 
healthcare for the majority of the population, and private eye healthcare for a minority of the population.

In the light of these unfortunate circumstances, the African National Congress (ANC) recognised the need for a complete transformation of the public healthcare system and consequently developed a National Health Plan (NHP) ${ }^{7}$ to redress the imbalances of the apartheid system. The aim of the $\mathrm{NHP}$ was to transform the public healthcare delivery system by reducing poverty and the waste of resources. The NHP also emphasised that all healthcare professionals were equally important and that teamwork should be the basis of the new public healthcare system. Other important components of the NHP were effective community participation, respect for human rights, and accountability towards users of healthcare facilities and the public at large, including the improving of service delivery efficiency and promoting greater control of health issues by individuals and communities. Although the proposed health reforms in the NHP did not mention the concept of health promotion, it is clear from the plan that the new approach in the public healthcare system would focus more on health promotion than medical care.

The first draft of the NHP was initiated by the Department of Health of the ANC together with the World Health Organization and United Nations Children's Fund in 1994. The document adopted a primary healthcare approach and also involved the Reconstruction and Development Programme involving all sectors of government. Thus, this document became the cornerstone of health development perspectives that were integral to the socio-economic development of the people of South Africa. As a consequence of the NHP, the NHI was proposed for implementation as documented in the green paper $^{8}$ released on 12 August 2011. Via the NHI, there is hope that eye care delivery in the public health sector will improve, and it further creates an opportunity for new regulations to be developed on how eye care services should be delivered in South Africa.

\section{The National Health Insurance and eye care}

According to the South African Department of Health, ${ }^{8}$ the NHI will be implemented over a period of 14 years and in three phases. During the implementation phases, the NHI will cover five key areas that are integral to its success. These key areas will also have a direct bearing on how eye care services in South Africa will be delivered, and include the following aspects:

\section{Service provision}

The provision of services is directly linked to accessibility and availability. ${ }^{9}$ The accessibility of services is linked to the availability of proper infrastructure development whereas the availability of services may be associated with the presence of medical equipment and human resources. ${ }^{9}$ The NHI green paper therefore seeks to address these issues for the successful implementation of this initiative. Also, it is important to note that the goal of health services provision is to improve health outcomes in the population and to respond to people's expectations, whilst reducing inequalities in both health and responsiveness. ${ }^{9}$ Therefore, these points have a direct consequence on the provision of eye care services for the people of South Africa in that health services provision also refers to the availability of human resources such as ophthalmic nurses, optometrists and ophthalmologists. The role of human resources such as eye care professionals should be integrated with health service inputs such as physical capital and consumables with resulting outputs that are personal health services. According to Steinwachs and Hughes, ${ }^{10}$ personal health services should be delivered individually in a form of therapy or rehabilitation and may generate positive externalities such as the provision of spectacles for improved visual efficiency. This means that the NHI will need to ensure that primary eye care practitioners such as optometrists are available at the primary level of care or that those who are in the private sector are contracted to the NHI to offer services to the general public.

\section{Population coverage}

According to the NHI green paper, ${ }^{8}$ the system will seek to improve access to quality healthcare for the entire population and also provide financial risk protection against healthrelated catastrophic expenditures. It will entail provision of healthcare without making payments, thus making healthcare service freely available. The system will also create fairness in the sharing of healthcare finance and other resources including skilled healthcare professionals such as ophthalmic nurses, optometrists and ophthalmologists. Unfortunately, the roles of ophthalmic nurses and optometrists in the NHI are not yet clearly defined, whereas it is expected that ophthalmologists will be placed at a tertiary level of care and will see patients as per the referral system that will be adopted. It is therefore expected that more ophthalmic nurses will be trained in order to meet the PHC requirements for the $\mathrm{NHI}$ and that optometry as a profession will be even more recognised in terms of its scope as defined in the Health Professions Act (Act no. 56 of 1974), Government Gazette No. 29748 of 2007,11 regulation 2, and as amended in Government Gazette No. 33546 of 2010,12 regulation 2. According to this Act, an optometrist is deemed a primary healthcare professional whose responsibilities include the performance of eye examinations on patients with the purpose of detecting visual errors in order to provide clear, comfortable and effective vision; and the correction of errors of refraction and related factors by the provision of spectacles, spectacle lenses, spectacle frames and the supply and fitting of contact lenses to the members of the public, and the maintenance thereof, and the provision of vision therapy to members of the public and the use of scheduled substances as approved by the board and the Medicines Control Council of South Africa (MCCSA) or by any means other than surgical procedures.

Interestingly, the MCCSA ${ }^{13}$ has recently approved the use of scheduled substances for diagnostic and therapeutic 
purposes in optometry. This may be seen as a sign that the NHI will provide optometry with a platform to execute its responsibilities even more extensively. Because optometrists form part of the PHC team, MCCSA approval will add a much more needed skill into the NHI initiative to the benefit of the majority of those in need of eye care services. Furthermore, as the NHI is intended to ensure equitable resource provision to both private and public healthcare sectors, primary eye care services and possibly visual aids acquisition such as spectacles, contact lenses, low vision devices etc., will be directly funded by the NHI with no co-payments, which is much to the benefit of the population. However, it is important to note that the NHI will adopt a capitation system; therefore, expensive assistive devices will not be covered and, in such cases, the patient may have to make a co-payment. Although optometry is currently largely private, those interested in joining the NHI to serve the public will do so voluntarily, as will be the case with the balance of the other healthcare professions.

In addition, the system will also adopt a sound referral system from primary to tertiary level of care. Because the focus will be on health promotion, the system will use family health teams that will provide home-based care services where necessary. Those patients who may require primary healthcare at a community clinic level will then be referred by a member of the family health team. According to Wootton, ${ }^{14}$ effective coverage of a health system is the main domain and the most inclusive construct of coverage, linking the individual health risk, probability of coverage, and effectiveness of interventions to each other. Therefore, the composition of the family health team will be determined by a system that will consider the kinds of health risk that can affect a given community. Most importantly, the family health team is likely to also focus on eye health care at a household level. However, it is important to recognise that the NHI approach will be based on the PHC system as recommended in the District Clinical Specialist Teams (DCSTs) report. ${ }^{15}$ The purpose of the DCSTs is to improve both the quality of healthcare and health outcomes for mothers, infants, toddlers and children. It will be composed of experts in the clinical disciplines such as obstetrics and gynaecology, paediatrics, nursing, family medicine and public health..$^{15}$ Therefore, the composition of the family health teams is likely to be similar to the DCSTs, consequently omitting eye care practitioners from the system at a community level.

\section{Financing}

In the first 5 years of the implementation phase, the focus will mainly be on public healthcare systems. ${ }^{8}$ Healthcare systems refer to the organisation, financing and delivery of public health services to communities and the impact of these services on public health. ${ }^{16}$ This focus further includes private sector entities that have responsibilities for providing public health services to the communities. Therefore, institutions such as the Brian Holden Vision Institute and the Siyabona Sonke, which have memorandums of understanding with provincial health departments in the Eastern and North-West
Provinces respectively, will play a major role in strengthening eye healthcare in South Africa as they continue to provide eye care services in rural communities. ${ }^{17}$ Although the NHI funding model is currently not well understood, except that the funds will be from the general tax revenue, it is also not clear how these institutions will be strengthened financially and also participate in the system.

According to the NHI green paper, ${ }^{8}$ a central fund for the NHI will be launched during the period 2014/2015. The fund will receive revenue from tax (contributions from both employers and employees), with the South African Revenue Services responsible for collection. All citizens will contribute to the fund, and those who choose to remain contracted to private medical schemes will do so at an additional cost. Consequently, belonging to both the NHI and a private medical scheme may not be possible owing to the high costs involved. Therefore all South Africans, regardless of creed, gender, race and social status will be compelled to contribute to the scheme. However, low-income earners, as may be determined by the finalised funding model, will be exempted from contributing to the NHI.

\section{Governance}

The NHI green paper recognises the importance of strengthening governance in the public healthcare system. It recognises that public healthcare facilities require a complete overhaul to meet the proposed standards of the NHI. This view is in line with Freedman's assertion ${ }^{18}$ that governance is critical in strengthening health systems and attaining Millennium Development Goals. According to Gilson and Daire, ${ }^{19}$ leadership is a necessary element of strong health systems, and therefore it is vital that South Africa nurtures and sustains leaders who can work strategically within their complex environments to develop a rights-based health system that promotes health equity, especially in the advent of the NHI system. Therefore, to improve the functioning systems of public healthcare facilities, radical changes in management and administration of community health centres and hospitals have to be made. Issues of funding, staffing and poor patient-doctor ratios should be drastically rectified through proper management and administration in healthcare institutions. These changes should then eliminate problems such as those in Northern Cape Province, where there are no optometrists in the public healthcare system. According to Sithole, ${ }^{17}$ only two optometrists are available in the public healthcare system of Western Cape Province. Such a lack of these important roleplayers in PHC will not meet the operational standards of the NHI if the governance structures surrounding this problem are not improved.

\section{Institutional arrangements}

Every institution will have to comply with core basic standards as may be outlined by a watchdog body called the Office of Health Standards and Compliance (OHSC) that was recently established by an act of parliament. The OHSC will monitor public health services and address complaints 
of non-compliance, whilst developing guidelines and providing information on the implementation of set health service standards. The OHSC will lead the much-needed improvement in health service quality, change in public health care management, and institution of core health standards in public and private service providers. This move will lay the groundwork for the rollout of the NHI initiative. Therefore, optometric clinics in both private and public sectors will have to meet certain set standards of compliance to participate in the NHI.

Interestingly, the South African Optometric Association (SAOA) is currently in the process of developing optometric clinical guidelines that may be incorporated into the standards and compliance requirements for optometrists to be contracted to the NHI initiative. However, proper systems must be put in place to ensure that the SAOA plays a major role as the custodians of optometric eye care in South Africa.

\section{Current progress and possible challenges on the implementation of the National Health Insurance}

\section{Current progress}

The NHI pilot project has already been launched in accordance with specifications in the green paper. In a study by Matsoso and Fryatt, ${ }^{20}$ it was reported that the national Department of Health has consulted with medical scheme administrators, labour, the pharmaceutical industry, professional associations for various occupations (including optometry and ophthalmology), statutory bodies, government departments, academia, civil society and parliament. The study further reported that, since the launch of the NHI green paper, over 100 submissions have been made to the Department of Health. ${ }^{15}$ The initiative has already started with pilot projects in 11 districts which were launched in April 2011, that include every province, focusing on underserved communities. ${ }^{20}$ Furthermore, international experience in defining healthcare packages has been studied and consequently a starting-point for South Africa is presumed to be a list of 'non-negotiable' services that should be adequately budgeted for and provided in all districts as per these studies. ${ }^{20}$ Also, a PHC platform is being established across the country, based on three complementary components:

- ward-based PHC with 40000 community health workers having been trained in the new PHC approach. Unfortunately, details on what the training entails are not available. It is therefore unclear whether some community health workers have adequate expertise for eye healthcare issues or not

- school health services where mobile healthcare clinics will visit schools and focus on preventive and health promotion services aimed at reducing barriers to learning and promoting access to other services. ${ }^{21}$ According to this policy, eye care professionals who may provide services at PHC level may not be part of the school health services, which poses a serious challenge to issues of eye health promotion at this level
- establishment of DCSTs across all provinces. Over $43 \%$ of positions have been filled so far, and the induction programme for these professionals is underway. ${ }^{20}$ Eye care personnel continue to be overlooked, including other important allied healthcare personnel who are vital for the success of the NHI at PHC level.

\section{Challenges}

The NHI initiative received a considerable amount of criticisms before its implementation, and the delay in releasing the white paper further compounds the uncertainties regarding the implementation of this initiative. In his response to some of the criticisms that compared South Africa with other international countries such as the USA, UK and Australia, SA Minister of Health Dr Aaron Motsoaledi depicted the state of the South African budget for this initiative in comparison with the former countries. ${ }^{22} \mathrm{He}$ indicated that there was a need to first establish their gross domestic products (GDPs), total per capita expenditure and the cost of living in each country. According to the minister, critics compare the health costs of the USA, UK, Australia and South Africa, but fail to point out that the GDP of the USA is $\$ 16$ trillion (21.9\% of the global economy), that of the UK is $\$ 2$ trillion and Australia's $\$ 961$ billion (2.1\% of the global economy), whereas South Africa's GDP is $\$ 576$ billion ( $0.5 \%$ of the global economy). The total per capita expenditure on health in the USA is \$51000, in the UK \$36000, and in Australia \$41000; South Africa's equivalent is $\$ 11000$ (All the preceding figures are in US dollars). In simple terms, the American and Australian economies are respectively 5 and 2 times the size of South Africa economy. These figures indicate that Americans spend 6.6 times per capita per year more on health than the South African private health sector - regardless of the fact that the USA economy is five times bigger than that of South Africa. In support of the minister's assertions, a study by $\mathrm{Amado}^{23}$ reported that, although the USA is the biggest economy in the world, some Americans were opposed to implementation of the National Health System, citing costs as concerns. Based on these concerns, it is therefore expected that some South Africans may be worried about the costs of implementing the NHI. These concerns may need to be addressed in the light of the social and economic challenges in South Africa.

According to Amado, ${ }^{23}$ the NHI is an idealistic proposition that has many other challenges to overcome, despite reported criticism on the feasibility of implementing this initiative. The first of these issues is reported to be corruption, which accounts for the waste of $10 \%$ of all healthcare expenditure in South Africa, and R5 billion - R15 billion within the private sector alone, ${ }^{24}$ and remains a major concern. Whilst corruption may be difficult to overcome, it is an issue that needs to be addressed before implementing the NHI. Lack of transparency is an important problem in South Africa and has resulted in many public outcries in the past. Therefore, to eliminate corruption, sytems must be in place to watch over the NHI's implementation. 
Other challenging issues may include spending of the budgeted allocations and poor infrastructure. According to Bateman, ${ }^{25}$ the provinces of KwaZulu-Natal, Eastern Cape, Free State, Limpopo and Northern Cape underspent their budget allocations for the programme to revitalise their health facilities by nearly $\mathrm{R} 2$ billion. In addition, preliminary findings of a high-level audit have revealed that most health facilities in Eastern Cape Province would have to close once the current Norms and Standards Bill became law, ${ }^{25}$ and would therefore not participate in the NHI owing to noncompliance. And, still in Eastern Cape Province, the DirectorGeneral of the Department of Health stated that 'condemned' health institutions continued operating out of necessity, with 168 clinics and 17 hospitals lacking piped water, and 42 health facilities lacking electricity and operating via generators. Also, $68 \%$ of hospitals lacked essential medical equipment and $16 \%$ of facilities had no telephone lines and were accessible by road only in good weather. Furthermore, overall staff vacancy rates stood at $46 \%$ (most clinical posts), requiring an unfeasible $\mathrm{R} 9$ billion extra to fill. Although the reported challenges are in Eastern Cape Province, it is possible that the situation may be similar in some other provinces in South Africa. If this is so, the NHI initiative will face insurmountable challenges to an extent that it may not be possible to implement.

According to Amado, ${ }^{23}$ challenges such as resource availability and financing must be addressed too. These issues may include poor infrastructure and standardisation of healthcare facilities. Different funding models for the initiative need to be explored and these should be communicated to the general public to dispel misconceptions about the initiative. With such problematic issues, it is doubtful whether eye care in the Eastern Cape or other provinces with similar challenges has been given the consideration it deserves. However, it is important to note that Eastern Cape Province fares much better than most other provinces (such as Western Cape, Northern Cape, Northwest and Mpumalanga) that have no or very few optometrists in their health departments, as shown in Figure 1.

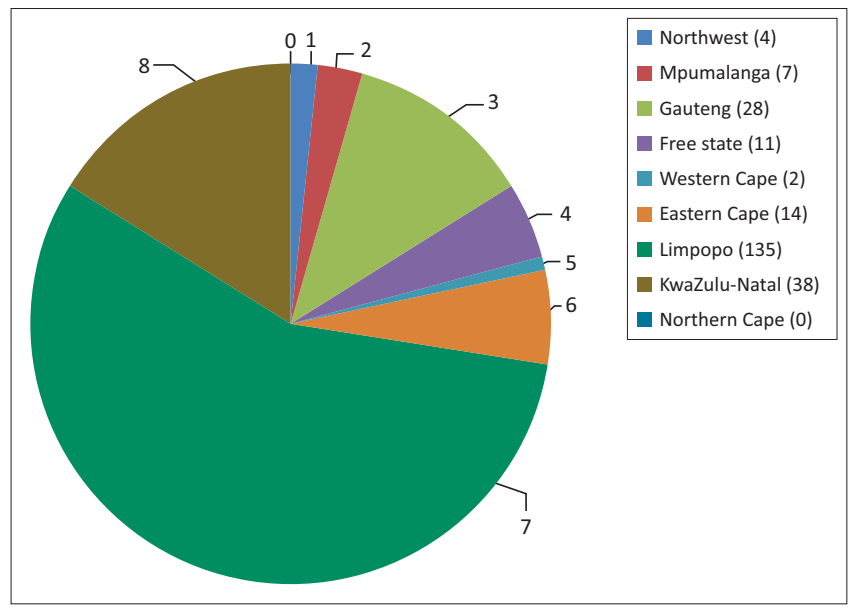

Source: Figure adapted from Sithole ${ }^{17}$

FIGURE 1: Distribution of the number of optometrists in the public health sector in South Africa. Northern Cape Province has no optometrists in the public health sector.

\section{Conclusion}

Details of how the NHI will be rolled out are still sketchy. The release of the white paper is expected to shed some light on the implementation processes including human resources, financing and poor infrastructure. Unfortunately, there still seems to be no adequate advocacy for eye health to be fully implemented as part of the NHI in the manner that eye healthcare professionals would expect. During the SAOA Conference held recently at the Cape Town International Convention Centre, the Chief Director from the Directorate of Chronic Diseases, Disability and Geriatrics reported that the establishment of a new directorate for eye healthcare is on the cards. In addition, the Chief Director alluded to the recent call for nominations for persons who would form part of the health minister's advisory committee on issues of eye healthcare as a major shift towards the recognition of eye health issues from government's perspective. Therefore, it remains to be seen whether the NHI will be fully implemented as envisaged in the policy and whether eye health will be incorporated into the entire system. Currently, eye healthcare issues remain in the periphery despite efforts to overhaul the entire public healthcare system, and include issues of eye health.

\section{Acknowledgements Competing interests}

The author declares that there are no financial or personal relationships which may have inappropriately influenced the writing of this article.

\section{References}

1. Lagarde $\mathrm{M}$, Palmer $\mathrm{N}$. The impact of user fees on access to health services in low and middle income countries. Cochrane Database Syst Rev 20114 CD009094. $\mathrm{http}: / / \mathrm{dx}$.doi.org/10.1002/14651858.CD009094

2. Du Toit R, Faal HB, Etya'ale $D$, et al. Evidence for integrating eye health into primary health care in Africa: A health systems strengthening approach. BMC Health Serv Res. 2013;13:102-116. http://dx.doi.org/10.1186/1472-6963-13-102

3. Odeyemi IAO, Nixon J. Assessing equity in health care through the national health insurance schemes of Nigeria and Ghana: A review-based comparative analysis. Int J Equity Health. 2013;12:9. http://dx.doi.org/10.1186/1475-9276-12-9

4. Sakyi E, Atinga RA, Adzei FA. Managerial problems of hospitals under Ghana's National Health Insurance Scheme. Int J Clin Gov. 2012;17(3):178-189. http://dx.doi.org/10.1108/14777271211251291

5. Ministry of Health. National Health Policy. October 2003. Ministry of Health, The United Republic of Tanzania.

6. The Economist. Africa's New Number One. April 2014. [cited 14 August 2014] Available from: http://www.economist.com/news/leaders/21600685-nigeriassuddenlysupersized-economy-indeed-wonder-so-are-its-still-huge

7. African National Congress. A National Health Plan for South Africa. May 1994.

8. National Department of Health. National Health Insurance in South Africa. Pretoria: National Department of Health; August 2011.

9. Adams O, Shengelia B, Stilwell B, et al. Provision of personal and non-personal health services: Proposal for monitoring. Geneva: World Health Organization; 2002.

10. Steinwachs DM, Hughes RG. Health services research: Scope and significance. Handbook for Nurses 2008;1:1-163.

11. National Department of Health. Health Professions Act, 1974 (Act 56 of 1974). Government Gazette No 29748, 5 April 2007. Pretoria: Government Printer; 5 April 2007.

12. South African Department of Health. Health Professions Act, 1974 (Act 56 of 1974). Government Gazette No 33546, 15 September 2010. Pretoria: Government Printer; 15 September 2010.

13. Medicines Control Council of South Africa. Prescription rights for optometrists. Pretoria: Medicines Control Council of South Africa; 7 October 2014.

14. Wootton R. Recent advances in telemedicine. J Br Med. 2001;323(8):557-560. http://dx.doi.org/10.1136/bmj.323.7312.557 
15. District clinical specialist teams in South Africa. Ministerial Task Team Report July 2012. [cited on 18 August 2014] Available from: http://www.doh.gov. za/docs/reports/2012/District_Clinical_Specialist_Teams_in_South_Africa_ za/docs/report.pdf

16. Leischow SJ, Milstein B. Systems thinking and modelling for public health practice. Am J Public Health. 2006;96:403-405. http://dx.doi.org/10.2105/ AJPH.2005.082842

17. Sithole HL. Critical analysis of the South African health care policies and programmes with regards to eye health promotion. DLitt et Phil Thesis, UNISA 2013.

18. Freedman LP. Who's got the power? Transforming health systems for women and children. London: Earthscan; 2005

19. Gilson L, Daire J. Leadership and governance within the South African Health System. SAHR. 2011;70-80.
20. Matsoso MP, Fryatt R. National health insurance: The first 18 months. S Afr Med J. 2013;103:156-158.

21. Department of Health, Department of Basic Education. Integrated school health policy. Pretoria: Department of Health and Department of Basic Education; October 2012

22. Motsoaledi A. Physician don't fool yourself - Motsoaledi responds to $\mathrm{NHI}$ criticism. Mail and Guardian. 7 February 2014 [cited 12 June 2014]. Available from http://mg.co.za/article/2014-02-06-physician-dont-fool-yourself

23. Amado L. National health insurance: A lofty ideal in need of cautious, planned implementation. S Afr J BL. 2012;5(1):4-10.

24. Dhai A. Healthcare reform in South Africa: A step in the right direction of social justice. S Afr J BL. 20.11;14:2.

25. Bateman C. Will our public healthcare sector fail the NHI? S Afr Med J. 2012;102(11):817-818. http://dx.doi.org/10.7196/samj.6358 